\title{
Effects of dexmedetomidine on perioperative stress response, inflammation and immune function in patients with different degrees of liver cirrhosis
}

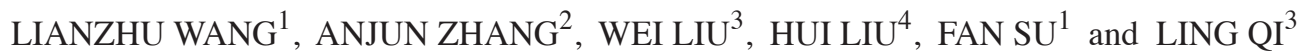 \\ ${ }^{1}$ Department of Anesthesiology, Affiliated Hospital of Shandong University of Traditional Chinese Medicine, \\ Jinan, Shandong 250014; ${ }^{2}$ Department of Anesthesiology, Rizhao City Hospital of Traditional Chinese Medicine, \\ Rizhao, Shandong 276800; ${ }^{3}$ Department of Anesthesiology, Jinan Maternity and Child Care Hospital, \\ Jinan, Shandong 250001; ${ }^{4}$ Department of Nursing, Affiliated Hospital of Shandong University \\ of Traditional Chinese Medicine, Jinan, Shandong 250014, P.R. China
}

Received February 12, 2018; Accepted August 6, 2018

DOI: $10.3892 /$ etm.2018.6665

\begin{abstract}
Effects of dexmedetomidine (DEX) on perioperative stress response, inflammation and immune function in patients with different degrees of liver cirrhosis were investigated. A total of 94 patients with liver cirrhosis who were admitted to the Affiliated Hospital of Shandong University of Traditional Chinese Medicine from December 2016 to November 2017 were included, and randomly divided into control and observation group $(n=47)$. Patients in control group were given remifentanil for anesthesia, while patients in observation group were treated with remifentanil and for DEX anesthesia. Venous blood was collected immediately before induction of anesthesia (T1), $10 \mathrm{~min}$ (T2) after the beginning of surgery, immediately after surgery (T3) and $2 \mathrm{~h}$ after surgery (T4). Hemodynamic parameters, stress response factors, adverse reactions and levels of inflammatory cytokines and $\mathrm{T}$ lymphocyte subsets were compared between the two groups. The mean arterial pressure in both groups was lower at T2-T4 than that at $\mathrm{T} 1(\mathrm{p}<0.05)$, and mean arterial pressure was lower in observation group than in control group $(\mathrm{p}<0.05)$. Visual analogue pain score $(\mathrm{VAS})$ of observation group was significantly lower than that of control group at 6 , 12 and $24 \mathrm{~h}$ after operation $(\mathrm{p}<0.05)$. There was no significant difference between the two groups in incidence of nausea, vomiting, hypoxemia and delayed awakening ( $p>0.05)$. Incidence of postoperative agitation in observation group was significantly lower than that in control group $(\mathrm{p}<0.05)$. The levels of $\mathrm{CD}^{+}, \mathrm{CD}^{+}$, and $\mathrm{CD}^{+} / \mathrm{CD}^{+}$in both groups
\end{abstract}

Correspondence to: Dr Ling Qi, Department of Anesthesiology, Jinan Maternity and Child Care Hospital, 2 Jianguoxiaojingsan Road, Shizhong, Jinan, Shandong 250001, P.R. China

E-mail: q0y427@163.com; qi_1@sina.com

Key words: dexmedetomidine, liver cirrhosis, immunity, stress response, inflammation were significantly lower at T2-T4 than those at $\mathrm{T} 1(\mathrm{p}<0.05)$. Levels of IL-10 and TNF- $\alpha$ in both groups were significantly higher at T2-T4 than those at T1, but levels of IL-2 and TNF- $\alpha$ were significantly lower in observation group than in control group $(\mathrm{p}<0.05)$. In conclusion, the use of DEX for anesthesia in patients with liver cirrhosis can improve hemodynamic stability, reduce stress response and reduce inflammation level without affecting immune function, which has important clinical significance.

\section{Introduction}

Cirrhosis is a common clinical disease of liver damage that can be caused by one or more factors (1). Hepatitis B is a viral infectious disease caused by hepatitis B virus (HBV). According to the WHO, $>350$ million people are currently infected with HBV in the world. Incidence of chronic HBV is high in China, and HBV infection is the main cause of cirrhosis (2). The main clinical manifestations of liver cirrhosis include liver dysfunction, tenderness, jaundice, bloating, abdominal pain, melena, ascites and lower extremity edema. The development of liver cirrhosis is slow, and is often accompanied by a variety of complications (hepatic encephalopathy, gastrointestinal bleeding and hepatorenal syndrome). Cirrhosis at decompensation stage may cause the occurrence of cancer, leading to poor prognosis (3). Studies have shown that occurrence of liver cancer is closely correlated with chronic hepatitis and cirrhosis (4). At present, effective treatment strategies for cirrhosis are lacking. Surgical resection is usually performed in the case of cancer, which is of positive significance to the prognosis. Surgery and anesthesia can cause stress responses in the body, which in turn lead to inflammatory response and immune function suppression (5). Dexmedetomidine (DEX), as an $\alpha_{2}$ adrenergic receptor agonist with central anti-sympathetic effect, has satisfactory sedative and certain anti-inflammatory effect but without respiratory depression, and is used increasingly by physicians in clinical perioperative anesthesia, and the effect is significant (6). In this study, patients with different liver cirrhosis were treated 
Table I. Comparison of general information between the two groups.

\begin{tabular}{lcccr}
\hline Items & Observation group $(\mathrm{n}=47)$ & Control group $(\mathrm{n}=47)$ & $\mathrm{t} / \chi^{2}$ & P-value \\
\hline Sex (male/female) & $28 / 19$ & $26 / 21$ & 0.044 & 0.835 \\
Age (years) & $30-68$ & $30-65$ & & \\
Average age (years) & $46.56 \pm 4.42$ & $46.85 \pm 3.53$ & 0.351 & 0.726 \\
Course of disease (months) & $5.63 \pm 3.13$ & $5.78 \pm 3.28$ & 0.227 & 0.821 \\
Liver function type (n, \%) & & & & \\
A level & $16(34.04)$ & $17(36.17)$ & 0.559 & 0.756 \\
B level & $19(40.43)$ & $21(44.68)$ & & \\
C level & $12(25.53)$ & $9(19.15)$ & & \\
\hline
\end{tabular}

with DEX anesthesia to analyze its impact on stress response, inflammation and immune function.

\section{Patients and methods}

General information. A total of 94 patients with liver cirrhosis who were admitted to the Affiliated Hospital of Shandong University of Traditional Chinese Medicine (Jinan, China) from December 2016 to November 2017 were included and randomly divided into control and observation group $(n=47)$. Inclusion criteria: i) patients with liver cirrhosis confirmed by imaging and pathological examination (7); ii) patients who received surgical treatment; iii) approved by the Ethics Committee of the Hospital, and patients signed informed consent. Exclusion criteria: i) patients with autoimmune diseases, mental diseases and cardiovascular and renal insufficiency; ii) patients with severe coagulation disorders and who received hormone therapy within 1 month before surgery. There was no significant difference in general information between the two groups ( $>0.05)$ (Table I). This study was approved by the Ethics Committee of the Affiliated Hospital of Shandong University of Traditional Chinese Medicine (Jinan, China). Signed informed consents were obtained from the patients or guardians.

\section{Method}

Anesthesia methods. Patients in both groups were fasted for $8 \mathrm{~h}$ before operation, and were intramuscularly injected with $0.5 \mathrm{mg}$ atropine (state approval no. H41021256; Suicheng Pharmaceutical Co., Ltd., Xinzheng, China) at half an hour before operation. Real-time monitoring of blood pressure (BP), electrocardiogram (ECG), oxygen saturation $\left(\mathrm{SpO}_{2}\right)$, heart rate (HR) and other vital signs was also performed. Patients in control group were treated with sufentanil for anesthesia: intravenous injection of propofol $(1.5 \mathrm{mg} / \mathrm{kg}$, state approval no. H20123138; Jiangsu Enhua Pharmaceutical Co., Ltd., Jiangsu, China), sufentanil $(0.2 \mu \mathrm{g} / \mathrm{kg}$, state approval no. H20054256; Yichang Renfu Pharmaceutical Co., Ltd., Yichang, China) and cisatracurium $(0.1 \mathrm{mg} / \mathrm{kg}$, state approval no. JX20110148; GlaxoSmithKline Manufacturing SpA, Verona, Italy) was performed to induce anesthesia. Tracheal intubation was performed with EEG bispectral index (BIS) $<55$, and then the tube was connected to ventilator (breathing ratio, 1/2; respiratory rate, 12-15 times/min; tidal volume, $8-9 \mathrm{ml} / \mathrm{kg}$ ). Intermittent administration of sufentanil was performed to maintain BIS value at 40-45; sufentanil dosage was adjusted according to changes in BIS values, and the floating range was $30 \%$. Patients in observation group were given DEX (state approval no. 20110097; Sichuan Guorui Pharmaceutical Co., Ltd., Sichuan, China) for anesthesia, and induction of anesthesia was performed in the same manner as the control group. Intravenous infusion of DEX was performed for $10 \mathrm{~min}$ at a dose of $1.0 \mu \mathrm{g} / \mathrm{kg}$ at half an hour before induction of anesthesia, followed by continuous infusion of DEX at a dose of $0.5 \mu \mathrm{g} / \mathrm{kg}$ until half an hour before the end of surgery.

Detection of indicators. Venous blood ( $3 \mathrm{ml})$ was collected immediately before induction of anesthesia (T1), $10 \mathrm{~min}$ (T2) after the beginning of surgery, immediately after surgery (T3) and $2 \mathrm{~h}$ after surgery (T4). Blood was centrifuged at $8,000 \times \mathrm{g}$ at $4^{\circ} \mathrm{C}$ for $15 \mathrm{~min}$ to separate serum. Percentage of $\mathrm{CD}^{+}, \mathrm{CD}^{+}$and $\mathrm{CD}^{+}$cell activity was detected by flow cytometry (Sysmex Partec GmbH, Görlitz, Germany). Serum levels of IL-10, TNF- $\alpha$, Cor, ALD and ACTH levels were measured by enzyme-linked immunosorbent assay (ELISA), and were determined by using corresponding kits (Thermo Fisher Scientific, Inc., Waltham, MA, USA) according to the manufacturer's instructions. OD values at $450 \mathrm{~nm}$ were measured by using a microplate reader (wavelength, $450 \mathrm{~nm}$; Bio-Rad Laboratories, Inc., Hercules, CA, USA) to calculate the concentration of IL-10, TNF- $\alpha$, Cor, ALD and ACTH.

Evaluation method. Classification of liver function was performed according to the modified Child-Pugh grading standards (8). Hepatic encephalopathy, ascites, serum bilirubin, serum albumin concentration and prothrombin time were scored (1-3 points), and higher scores represent worse liver reserve function. Liver cirrhosis was divided into level $\mathrm{A}$ (5-6 points), B (7-9 points) and C (10-15 points) according to the total score.

Comparison of HR, MAP, $\mathrm{SpO}_{2}$ and $\mathrm{PETCO}_{2}$ between the two group at T1-T4, and comparison of visual analogue pain score (VAS) at 6, 12 and $24 \mathrm{~h}$ after operation were performed.

Venous blood was collected from patients at T1-T4. Levels of $\mathrm{T}$ lymphocyte subsets $\left(\mathrm{CD}^{+}, \mathrm{CD}^{+}, \mathrm{CD} 8^{+}, \mathrm{CD} 4^{+} / \mathrm{CD} 8^{+}\right)$ were measured by flow cytometry. Levels of IL-10, TNF- $\alpha$, Cor, ALD and ACTH were measured by using ELISA. Postoperative adverse reactions, including nausea, vomiting, hypoxemia, delayed wakefulness and postoperative agitation were recorded and compared. 
Table II. Comparison of hemodynamic indicators between the two groups at different time-points.

\begin{tabular}{|c|c|c|c|c|c|c|}
\hline Items & Groups & Cases & $\mathrm{T} 1$ & $\mathrm{~T} 2$ & $\mathrm{~T} 3$ & $\mathrm{~T} 4$ \\
\hline \multirow[t]{2}{*}{ HR (times) } & Observation & 47 & $84.76 \pm 8.14$ & $74.56 \pm 7.48$ & $68.16 \pm 6.15$ & $64.86 \pm 5.53$ \\
\hline & Control & 47 & $85.36 \pm 8.15$ & $75.15 \pm 7.57$ & $67.83 \pm 6.27$ & $65.24 \pm 5.64$ \\
\hline \multirow[t]{2}{*}{$\mathrm{SPO}_{2}(\mathrm{mmHg})$} & Observation & 47 & $99.49 \pm 0.44$ & $98.65 \pm 0.34$ & $97.46 \pm 0.38$ & $99.56 \pm 0.13$ \\
\hline & Control & 47 & $99.54 \pm 0.31$ & $98.38 \pm 0.21$ & $97.32 \pm 0.42$ & $99.51 \pm 0.26$ \\
\hline \multirow[t]{2}{*}{$\mathrm{PETCO}_{2}(\mathrm{mmHg})$} & Observation & 47 & $35.62 \pm 1.36$ & $35.34 \pm 1.31$ & $35.48 \pm 1.23$ & $35.53 \pm 1.31$ \\
\hline & Control & 47 & $35.81 \pm 1.52$ & $35.76 \pm 1.65$ & $35.89 \pm 1.42$ & $35.28 \pm 1.29$ \\
\hline
\end{tabular}

Table III. Comparison of MAP at different time-points ( $\mathrm{mmHg})$.

\begin{tabular}{lccccc}
\hline Groups & Cases & T1 & T2 & T3 & T4 \\
\hline Observation & 47 & $56.69 \pm 3.52$ & $68.24 \pm 4.43^{\mathrm{a}}$ & $65.76 \pm 3.28^{\mathrm{a}}$ & $63.74 \pm 3.47^{\mathrm{a}}$ \\
Control & 47 & $57.12 \pm 3.64$ & $79.67 \pm 4.64^{\mathrm{a}}$ & $75.58 \pm 3.45^{\mathrm{a}}$ & $69.38 \pm 3.35^{\mathrm{a}}$ \\
t-test & & 0.582 & 12.215 & 14.142 & 8.017 \\
P-value & & 0.562 & $<0.001$ & $<0.001$ & $<0.001$ \\
\hline
\end{tabular}

${ }^{\mathrm{a}} \mathrm{P}<0.05$, compared with $\mathrm{T} 1$.

Table IV. Comparison of VAS after operation ( $\overline{\mathrm{x}} \pm \mathrm{s}$, points).

\begin{tabular}{lcccc}
\hline Groups & Cases & $\begin{array}{c}6 \mathrm{~h} \text { after } \\
\text { operation }\end{array}$ & $\begin{array}{c}12 \mathrm{~h} \text { after } \\
\text { operation }\end{array}$ & $\begin{array}{c}24 \mathrm{~h} \text { after } \\
\text { operation }\end{array}$ \\
\hline Observation & 47 & $1.36 \pm 0.18$ & $1.13 \pm 0.27$ & $2.13 \pm 1.12$ \\
Control & 47 & $1.73 \pm 0.26$ & $1.86 \pm 0.31$ & $3.56 \pm 1.17$ \\
t-test & & 8.021 & 12.174 & 6.053 \\
P-value & & $<0.001$ & $<0.001$ & $<0.001$ \\
\hline
\end{tabular}

VAS, visual analogue pain score.

Statistical analysis. Data were processed by SPSS 19.0 (SPSS Inc., Chicago, IL, USA) software. Measurement data are expressed as mean \pm standard deviation (SD) and compared by $\mathrm{t}$-test. Enumeration data are expressed as rate and compared by using $\chi^{2}$ test. ANOVA was used for comparison between multiple groups and the post hoc test was SNK test. $\mathrm{P}<0.05$, a statistically significant difference.

\section{Results}

Comparison of hemodynamic indicators between the two groups at different time-points. There was no significant difference in $\mathrm{HR}, \mathrm{SpO}_{2}$ and $\mathrm{PETCO}_{2}$ between the two groups at different time-points $(\mathrm{p}>0.05)$ (Table II).

Comparison of MAP at different time-points. Compared with $\mathrm{T} 1, \mathrm{MAP}$ increased at T2, T3 and T4 in both groups. MAP was significantly lower in observation group than that in control group $(\mathrm{p}<0.05)$ (Table III).
Comparison of VAS after operation. VAS at 6, 12 and $24 \mathrm{~h}$ after operation was significantly lower in observation group than that in control group $(\mathrm{p}<0.05)$ (Table IV).

Comparison of perioperative stress response between the two groups. Compared with T1, Cor, ALD and ACTH levels significantly increased in both groups at $\mathrm{T} 2, \mathrm{~T} 3$ and $\mathrm{T} 4$, but Cor, ALD and ACTH levels were significantly lower in observation group than those in control group $(\mathrm{p}<0.05)$ (Table V).

Comparison of adverse reactions between the two groups. No significant differences in incidence of nausea and vomiting, hypoxemia and delayed wakefulness were found between the two groups $(\mathrm{p}>0.05)$. Incidence of postoperative agitation was significantly lower in observation group than that in control group $(\mathrm{p}<0.05)($ Table VI).

Comparison of perioperative inflammation levels between the two groups. Compared with T1, the levels of IL-10 and $\mathrm{TNF}-\alpha$ in the two groups were significantly increased at T2, T3 and T4. In addition, levels of IL-10 and TNF- $\alpha$ were significantly lower in observation group than those in control group $(\mathrm{p}<0.05)$ (Table VII).

Comparison of perioperative $T$ lymphocyte subsets between the two groups. Levels of $\mathrm{CD}^{+}, \mathrm{CD} 4^{+}$and $\mathrm{CD} 4^{+} / \mathrm{CD} 8^{+}$were significantly lower at $\mathrm{T} 2-\mathrm{T} 4$ than those at $\mathrm{T} 1(\mathrm{p}<0.05)$. There was no significant difference in $\mathrm{CD}^{+}$between the two groups (p>0.05) (Table VIII).

\section{Discussion}

Cirrhosis as a common chronic disease, and usually caused by alcoholic liver damage, viral hepatitis and autoimmune 
Table V. Comparison of perioperative stress response between the two groups.

\begin{tabular}{lcccccc}
\hline Items & Groups & Cases & T1 & T2 & T3 & T4 \\
\hline Cor $(\mathrm{ng} / \mathrm{ml})$ & Observation & 47 & $184.73 \pm 8.14$ & $214.56 \pm 7.48^{\mathrm{a}, \mathrm{b}}$ & $238.16 \pm 6.15^{\mathrm{a}, \mathrm{b}}$ & $203.86 \pm 6.52^{\mathrm{a}, \mathrm{b}}$ \\
& Control & 47 & $185.36 \pm 8.15$ & $235.15 \pm 7.53^{\mathrm{a}}$ & $267.83 \pm 6.27^{\mathrm{a}}$ & $219.24 \pm 6.63^{\mathrm{a}}$ \\
ALD $(\mathrm{pg} / \mathrm{ml})$ & Observation & 47 & $96.46 \pm 3.48$ & $129.63 \pm 4.34^{\mathrm{a}, \mathrm{b}}$ & $139.46 \pm 5.38^{\mathrm{a}, \mathrm{b}}$ & $130.56 \pm 0.17^{\mathrm{a}, \mathrm{b}}$ \\
& Control & 47 & $96.51 \pm 3.35$ & $172.38 \pm 4.28^{\mathrm{a}}$ & $248.32 \pm 5.45^{\mathrm{a}}$ & $203.51 \pm 0.28^{\mathrm{a}}$ \\
ACTH $(\mathrm{pmol} / \mathrm{l})$ & Observation & 47 & $9.64 \pm 1.36$ & $29.34 \pm 3.35^{\mathrm{a}, \mathrm{b}}$ & $31.48 \pm 3.25^{\mathrm{a}, \mathrm{b}}$ & $26.53 \pm 3.32^{\mathrm{a}, \mathrm{b}}$ \\
& Control & 47 & $9.82 \pm 1.52$ & $38.76 \pm 3.63^{\mathrm{a}}$ & $42.89 \pm 3.47^{\mathrm{a}}$ & $32.28 \pm 3.26^{\mathrm{a}}$ \\
\hline
\end{tabular}

${ }^{\mathrm{a}} \mathrm{P}<0.05$, compared with $\mathrm{T} 1 ;{ }^{\mathrm{b}} \mathrm{p}<0.05$, compared with control group.

Table VI. Comparison of adverse reactions between the two groups (n, \%).

\begin{tabular}{lccccc}
\hline Items & Groups & Nausea and vomiting & Hypoxemia & Postoperative agitation & Delayed wakefulness \\
\hline Observation & 47 & $3(6.38)$ & $1(2.13)$ & $0(0.00)$ & $2(4.26)$ \\
Control & 47 & $5(10.64)$ & $3(6.38)$ & $6(12.77)$ & $4(8.51)$ \\
$\chi^{2}$ & & 0.137 & 0.261 & 4.451 & 0.178 \\
P-value & & 0.712 & 0.609 & 0.035 & 0.673 \\
\hline
\end{tabular}

Table VII. Comparison of perioperative inflammation levels between the two groups.

\begin{tabular}{lcccccc}
\hline Items & Groups & Cases & T1 & T2 & T3 & T4 \\
\hline IL-10 (ng/l) & Observation & 47 & $144.92 \pm 8.23$ & $153.53 \pm 8.49^{\mathrm{a}, \mathrm{b}}$ & $168.36 \pm 8.15^{\mathrm{a}, \mathrm{b}}$ & $174.76 \pm 8.52^{\mathrm{a}, \mathrm{b}}$ \\
& Control & 47 & $145.38 \pm 8.45$ & $165.45 \pm 8.57^{\mathrm{a}}$ & $187.84 \pm 8.29^{\mathrm{a}}$ & $215.35 \pm 8.63^{\mathrm{a}}$ \\
TNF- $\alpha(\mathrm{ng} / \mathrm{l})$ & Observation & 47 & $63.23 \pm 3.54$ & $68.62 \pm 3.74^{\mathrm{a}, \mathrm{b}}$ & $73.43 \pm 3.38^{\mathrm{a}, \mathrm{b}}$ & $79.46 \pm 3.57^{\mathrm{a}, \mathrm{b}}$ \\
& Control & 47 & $63.17 \pm 3.49$ & $79.37 \pm 3.86^{\mathrm{a}}$ & $84.57 \pm 3.45^{\mathrm{a}}$ & $92.52 \pm 3.98^{\mathrm{a}}$ \\
\hline
\end{tabular}

${ }^{\mathrm{a}} \mathrm{P}<0.05$, compared with $\mathrm{T} 1 ;{ }^{\mathrm{b}} \mathrm{p}<0.05$, compared with control group.

Table VIII. Comparison of perioperative T lymphocyte subsets between the two groups.

\begin{tabular}{lccccc}
\hline Items & Groups & $\mathrm{T} 1$ & $\mathrm{~T} 2$ & $\mathrm{~T} 3$ & $\mathrm{~T} 4$ \\
\hline $\mathrm{CD}^{+}(\%)$ & Control & $54.83 \pm 9.54$ & $43.56 \pm 6.45^{\mathrm{a}, \mathrm{b}}$ & $44.74 \pm 3.66^{\mathrm{a}, \mathrm{b}}$ & $46.74 \pm 3.63^{\mathrm{a}, \mathrm{b}}$ \\
& Observation & $55.36 \pm 9.35$ & $45.86 \pm 6.37^{\mathrm{a}}$ & $51.47 \pm 4.73^{\mathrm{a}}$ & $51.47 \pm 4.78^{\mathrm{a}}$ \\
$\mathrm{CD}^{+}(\%)$ & Control & $32.56 \pm 6.45$ & $22.36 \pm 3.38^{\mathrm{a}, \mathrm{b}}$ & $21.48 \pm 3.87^{\mathrm{a}, \mathrm{b}}$ & $24.48 \pm 3.25^{\mathrm{a}, \mathrm{b}}$ \\
& Observation & $33.21 \pm 6.32$ & $25.42 \pm 3.45^{\mathrm{a}}$ & $27.25 \pm 3.65^{\mathrm{a}}$ & $29.25 \pm 3.45^{\mathrm{a}}$ \\
$\mathrm{CD}^{+}(\%)$ & Control & $21.74 \pm 3.06$ & $20.46 \pm 2.35^{\mathrm{a}, \mathrm{b}}$ & $21.56 \pm 2.14^{\mathrm{a}, \mathrm{b}}$ & $21.53 \pm 2.26^{\mathrm{a}, \mathrm{b}}$ \\
& Observation & $21.92 \pm 3.12$ & $20.83 \pm 2.47^{\mathrm{a}}$ & $21.24 \pm 2.18^{\mathrm{a}}$ & $21.47 \pm 2.38^{\mathrm{a}}$ \\
$\mathrm{CD}^{+} / \mathrm{CD} 8^{+}$ & Control & $1.54 \pm 0.36$ & $1.12 \pm 0.47^{\mathrm{a}, \mathrm{b}}$ & $1.06 \pm 0.34^{\mathrm{a}, \mathrm{b}}$ & $1.16 \pm 0.32^{\mathrm{a}, \mathrm{b}}$ \\
& Observation & $1.52 \pm 0.32$ & $1.21 \pm 0.45^{\mathrm{a}}$ & $1.28 \pm 0.28^{\mathrm{a}}$ & $1.47 \pm 0.48^{\mathrm{a}}$ \\
\hline
\end{tabular}

${ }^{\mathrm{a}} \mathrm{P}<0.05$, compared with $\mathrm{T} 1 ;{ }^{\mathrm{b}} \mathrm{p}<0.05$, compared with control group.

hepatitis (9). Liver cirrhosis at early stage lacks classic symptoms, and the progression is slow (may last for 3-10 years). However, liver cirrhosis caused by severe hepatitis progresses rapidly, and extensive necrosis of liver cells may occur in a short period of time, leading to severely damaged liver function and poor prognosis (10). 
Pathological changes of liver cirrhosis include fibrosis of the liver, diffuse necrosis and nodular regeneration of liver cells, changes in hepatic blood circulation, liver damage, and even carcinogenesis (11).

DEX is a selective $\alpha_{2}$ adrenergic receptor agonist that can suppress various stress responses, and thus maintains hemodynamic stability (12). Results of this study showed no significant difference in the perioperative $\mathrm{HR}, \mathrm{SpO}_{2}$ and $\mathrm{PETCO}_{2}$ between the two groups ( $\left.\mathrm{p}>0.05\right)$. MAP and VAS scores in observation group were significantly lower than those in control group $(\mathrm{p}<0.05)$. This is because DEX can reduce intraoperative hypertension response in cirrhotic patients, and regulate the elevated BP by activating the $\alpha_{2}$ receptor in the motor neuron complex. At the same time, DEX can produce hypnosis effect by activating $\mathrm{K}^{+}$channel to promote $\mathrm{K}^{+}$signal conduction, and activating endogenous sleep-promoting pathway to produce hypnotic effect, and the analgesic effect is significant (13). After entering cerebrospinal fluid, DEX can bind to the locus coeruleus $\alpha_{2}$ receptor, which effectively inhibits histamine release from cortical and subcortical projection systems, and reduces sympathetic tone, and enhances vagal activity to achieve satisfactory intraoperative analgesic effect. In addition, DEX also has posterior effect, which can achieve analgesic effect after surgery (14).

Surgery and anesthesia can cause stress response in the body, and Cor can effectively reflect stress levels in patients after surgery (15). ALD is a hormone that regulates blood volume. ALD is regulated by renin-angiotensin, and the amount of its secretion was negatively correlated with circulating blood volume (16). ACTH can be used as an objective indicator of the level of stress response (17). Results of this study showed that Cor, ALD and ACTH levels were significantly increased in both groups during the perioperative period, and the levels were significantly lower in observation group than those in control group $(\mathrm{p}<0.05)$. This is because surgery and anesthesia stimulation can increase the patient's stress response, leading to secretion of excessive Cor, ALD and ACTH, while DEX has a unique anti-injury effect. In this study, the advanced defensive analgesia can reduce the central sensitization, and adrenergic $\alpha_{2}$ receptor is highly selectively activated through the role of locus coeruleus nucleus, thereby inhibiting the release of ACTH and reducing ALD level by increasing circulating blood volume. In addition, DEX can reduce the body's response to stimulus, and inhibit nerve excitement, thereby reducing patient's stress response.

In this study, no significant differences in incidence of nausea and vomiting, hypoxemia and delayed wakefulness were found between the two groups $(p>0.05)$. Incidence of postoperative agitation was significantly lower in observation group than that in control group $(\mathrm{p}<0.05)$. This is because DEX can inhibit $\mathrm{Ca}^{2+}$ influx in nerve endings, and decreases the postsynaptic membrane excitability, thereby reducing body temperature threshold of chills, and reducing vasoconstriction, preventing chills, and reducing the incidence of postoperative agitation (18).

Stress reaction will inhibit the patient's immunity and other functions, so immune dysfunction and inflammatory reactions usually occur in patients after surgery (19). CD4+ belongs to the class of regulatory $\mathrm{T}$ cells with positive immunological regulation effect, while $\mathrm{CD}^{+}$has negative immunological regulation effect. Abnormal $\mathrm{CD}^{+} / \mathrm{CD}^{+}$ratio in the body may cause immune stability (20). In this study, levels of $\mathrm{CD}^{+}, \mathrm{CD}^{+}{ }^{+}$and $\mathrm{CD} 4^{+} / \mathrm{CD}^{+}$were significantly reduced during perioperative period. In contrast, levels of IL-10 and TNF- $\alpha$ were significantly increased, and the increases were more significant in control group $(\mathrm{p}<0.05)$. This is because the stress reaction will lead to increased catechol secretion, thereby inhibiting the immune function, and promoting the release of IL-10 and TNF- $\alpha$, so as to trigger inflammatory reactions. DEX can inhibit the sympathetic nerve, and reduce the release of catechins, which can exert direct and indirect effects on immune cells, and maintain autoimmune stability. In addition, $\mathrm{DEX}$ can regulate $\mathrm{NF}-\kappa \mathrm{B}$ pathway by activating cholinergic anti-inflammatory pathway, which can inhibit the release of IL-10 and TNF- $\alpha$ to achieve anti-inflammatory effects (21).

In conclusion, the use of DEX for anesthesia in patients with liver cirrhosis can improve hemodynamic stability, reduce stress response, and reduce inflammation level without affecting immune function.

\section{Acknowledgements}

Not applicable.

\section{Funding}

No funding was received.

\section{Availability of data and materials}

The datasets used and/or analyzed during the current study are available from the corresponding author on reasonable request.

\section{Authors' contributions}

LW drafted the study and revised it critically for important intellectual content. AZ, WL, HL and LQ were responsible for the conception and design of the work. LW, FS and LQ were responsible for the acquisition, analysis and interpretation of data for the study. All authors read and approved the final manuscript.

\section{Ethics approval and consent to participate}

This study was approved by the Ethics Committee of the Affiliated Hospital of Shandong University of Traditional Chinese Medicine (Jinan, China). Signed informed consents were obtained from the patients or guardians.

\section{Patient consent for publication}

Not applicable.

\section{Competing interests}

The authors declare that they have no competing interests. 


\section{References}

1. Curry MP, O'Leary JG, Bzowej N, Muir AJ, Korenblat KM, Fenkel JM, Reddy KR, Lawitz E, Flamm SL, Schiano T, et al; ASTRAL-4 Investigators: Sofosbuvir and velpatasvir for $\mathrm{HCV}$ in patients with decompensated cirrhosis. N Engl J Med 373: 2618-2628, 2015

2. Reddy KR, Bourlière M, Sulkowski M, Omata M, Zeuzem S, Feld JJ, Lawitz E, Marcellin P, Welzel TM, Hyland R, et al: Ledipasvir and sofosbuvir in patients with genotype 1 hepatitis $C$ virus infection and compensated cirrhosis: An integrated safety and efficacy analysis. Hepatology 62: 79-86, 2015.

3. Bourlière M, Bronowicki JP, de Ledinghen V, Hézode C, Zoulim F, Mathurin P, Tran A, Larrey DG, Ratziu V, Alric L, et al: Ledipasvir-sofosbuvir with or without ribavirin to treat patients with HCV genotype 1 infection and cirrhosis non-responsive to previous protease-inhibitor therapy: A randomised, double-blind, phase 2 trial (SIRIUS). Lancet Infect Dis 15: 397-404, 2015.

4. Fernández-Rodríguez CM and Gutiérrez-García ML: Prevention of hepatocellular carcinoma in patients with chronic hepatitis B. World J Gastrointest Pharmacol Ther 5: 175-182, 2014.

5. Movasseghi G, Hassani V, Mohaghegh MR, Safaeian R, Safari S, Zamani MM and Nabizadeh R: Comparison between spinal and general anesthesia in percutaneous nephrolithotomy. Anesth Pain Med 4: e13871-e13871, 2013.

6. Gerresheim G, Brederlau J and Schwemmer U: Dexmedetomidine in the treatment of acute alcohol withdrawal delirium. Anaesthesist 65: 525-531, 2016 (In German).

7. Scaglione S, Kliethermes S, Cao G, Shoham D, Durazo R, Luke A and Volk ML: The epidemiology of cirrhosis in the United States: A population-based study. J Clin Gastroenterol 49: 690-696, 2015.

8. Ogasawara S, Chiba T, Ooka Y, Kanogawa N, Saito T, Motoyama T, Suzuki E, Tawada A, Kanai F and Yokosuka O: Sorafenib treatment in Child-Pugh A and B patients with advanced hepatocellular carcinoma: Safety, efficacy and prognostic factors. Invest New Drugs 33: 729-739, 2015.

9. Younossi ZM, Otgonsuren M, Henry L, Venkatesan C, Mishra A, Erario $M$ and Hunt S: Association of nonalcoholic fatty liver disease (NAFLD) with hepatocellular carcinoma (HCC) in the United States from 2004 to 2009. Hepatology 62: 1723-1730, 2015.

10. Foster GR, Irving WL, Cheung MC, Walker AJ, Hudson BE, Verma S, McLauchlan J, Mutimer DJ, Brown A, Gelson WT, et al; HCV Research, UK: Impact of direct acting antiviral therapy in patients with chronic hepatitis $\mathrm{C}$ and decompensated cirrhosis. $\mathrm{J}$ Hepatol 64: 1224-1231, 2016.

11. Kim SK, Pak HN, Park JH, Choi JI, Nam MH, Jo Y and Kim YH: Non-ischaemic titrated cardiac injury caused by radiofrequency catheter ablation of atrial fibrillation mobilizes CD34-positive mononuclear cells by non-stromal cell-derived factor-1alpha mechanism. Europace 11: 1024-1031, 2009.
12. Bell MT, Agoston VA, Freeman KA, Puskas F, Herson PS, Mares J, Fullerton DA and Reece TB: Interruption of spinal cord microglial signaling by alpha- 2 agonist dexmedetomidine in a murine model of delayed paraplegia. J Vasc Surg 59: 1090-1097, 2014.

13. Krimins RA, Ko JC, Weil AB and Payton ME: Evaluation of anesthetic, analgesic, and cardiorespiratory effects in dogs after intramuscular administration of dexmedetomidine-butorphanoltiletamine-zolazepam or dexmedetomidine-tramadol-ketamine drug combinations. Am J Vet Res 73: 1707-1714, 2012.

14. Nazarov R, Kondratiev A, Rumiantseva M and Petrova A: Comparison of clonidine and dexmedetomidin influence on the main indicators of hemodynamic during induction of anesthesia in neurooncological patients. Intens Care Med Exp 3 (Suppl 1): A988, 2015.

15. Markou A, Sertedaki A, Kaltsas G, Androulakis II, Marakaki C, Pappa T, Gouli A, Papanastasiou L, Fountoulakis S, Zacharoulis A, et al: Stress-induced aldosterone hyper-secretion in a substantial subset of patients with essential hypertension. J Clin Endocrinol Metab 100: 2857-2864, 2015.

16. Fang VS, Tricou BJ, Robertson A and Meltzer HY: Plasma ACTH and cortisol levels in depressed patients: Relation to dexamethasone suppression test. Life Sci 29: 931-938, 1981.

17. Funai Y, Pickering AE, Uta D, Nishikawa K, Mori T, Asada A, Imoto $\mathrm{K}$ and Furue H: Systemic dexmedetomidine augments inhibitory synaptic transmission in the superficial dorsal horn through activation of descending noradrenergic control: An in vivo patch-clamp analysis of analgesic mechanisms. Pain 155: 617-628, 2014.

18. Sun L, Guo R and Sun L: Dexmedetomidine for preventing sevoflurane-related emergence agitation in children: A meta-analysis of randomized controlled trials. Acta Anaesthesiol Scand 58: 642-650, 2014.

19. Pearson AM and Lurie JD: Surgical versus nonoperative treatment: How do we choose the right approach to lumbar disk herniation? Pain Manag 4: 247-249, 2014.

20. Hung MH, Chan KC, Liu YJ, Hsu HH, Chen KC, Cheng YJ and Chen JS: Nonintubated thoracoscopic lobectomy for lung cancer using epidural anesthesia and intercostal blockade: A retrospective cohort study of 238 cases. Medicine (Baltimore) 94: e727, 2015.

21. Bulow NM, Colpo E, Pereira RP, Correa EF, Waczuk EP, Duarte MF and Rocha JB: Dexmedetomidine decreases the inflammatory response to myocardial surgery under mini-cardiopulmonary bypass. Braz J Med Biol Res 49: e4646, 2016.

This work is licensed under a Creative Commons Attribution-NonCommercial-NoDerivatives 4.0 International (CC BY-NC-ND 4.0) License. 